\title{
Avaliação nutricional e metabólica de borregas alimentadas com níveis crescentes de aminoácidos protegidos
}

[Nutritional and metabolic evaluation of feeding lambs with growing levels Of protein amino acids]

\author{
C.M. Araújo ${ }^{1}$, G.L. Macedo Júnior ${ }^{2}$, K.A. Oliveira ${ }^{3}$, A.L. Silva ${ }^{4}$, M.T.S. Santos ${ }^{4}$ \\ ${ }^{1}$ Aluno de pós-graduação - Universidade Federal de Uberlândia - Uberlândia, MG \\ ${ }^{2}$ Universidade Federal de Uberlândia - Uberlândia, MG \\ ${ }^{3}$ Aluna de pós-graduação - Universidade Estadual Paulista- Jaboticabal, SP \\ ${ }^{4}$ Aluno de graduação - Universidade Federal de Uberlândia - Uberlândia, MG
}

\section{RESUMO}

Objetivou-se avaliar a inclusão de níveis de lisina e metionina protegidas na dieta sobre os parâmetros nutricionais e metabólicos energéticos e hepáticos de borregas em crescimento. Utilizaram-se cinco borregas $1 / 2$ sangue Dorper x Santa Inês, com aproximadamente oito meses de idade e peso médio de $50 \pm 2,3 \mathrm{~kg}$, distribuídas em esquema quadrado latino $5 \times 5$ (cinco tratamentos, cinco animais e cinco períodos). Os tratamentos consistiram na inclusão de diferentes níveis de lisina e metionina protegidas da degradação ruminal (MicroPEARLS LM ${ }^{\circledR}$ ) na ração, sendo: $0 \mathrm{~g}, 8 \mathrm{~g}, 16 \mathrm{~g}, 24 \mathrm{~g}$ e $32 \mathrm{~g}$ por dia. A dieta era composta por silagem de milho e concentrado na relação 30V:70C. Realizou-se um ensaio de digestibilidade para determinar consumo e digestibilidade da matéria seca (CMS/DGMS), balanço de nitrogênio e metabólitos sanguíneos. O CMS (kg/dia) em relação ao peso metabólico apresentou equação linear positiva, sendo maior no tratamento que ofertou $32 \mathrm{~g}$ de aminoácidos por dia, assim como o nitrogênio ingerido e o balanço de nitrogênio, sendo positivo em todos os tratamentos. Não houve diferença $(\mathrm{P}>0,05)$ para a digestibilidade da MS e o metabolismo energético e hepático. Lisina e metionina protegidas da degradação ruminal podem ser incluídas na ração de borregas em crescimento até $32 \mathrm{~g} / \mathrm{dia}$ sem causar efeitos negativos na digestibilidade da MS e no metabolismo.

Palavras-chave: consumo de matéria seca, digestibilidade, energético, hepático, ovinos

\begin{abstract}
The objective was to evaluate the inclusion of protected lysine and methionine levels on the diet, over the nutritional parameters and energetic and hepatic metabolites of growing lambs. Five lambs $1 / 2$ blood Dorper $x$ Santa Inês, with approximately eight months of age and average weight of 50kg, were distributed in a $5 \times 5$ latin square scheme (five treatments and five replicates). The treatments consisted of the inclusion of different levels of lysine and methionine protected from ruminal degradation (MicroPEARLS LM ${ }^{\circledR}$ ) in the diet, being: $0 g$, 8g, $16 \mathrm{~g}, 24 \mathrm{~g}$ and $32 \mathrm{~g}$. The diet was composed of corn silage and concentrated 30V:70C in the ratio. A digestibility assay was performed to determine dry matter intake and digestibility (DMI/DDMI), nitrogen balance and blood metabolites. The DMI ( $\mathrm{kg} / \mathrm{day})$ in relation to the metabolic weight had a positive linear equation, being higher in treatment 32g, as well as the ingested nitrogen and nitrogen balance, being positive in all treatments. There was no difference $(P>0.05)$ for the digestibility of DM, energetic and hepatic metabolism. Lysine and methionine protected from ruminal degradation can be included in the diet of growing lambs up to $32 \mathrm{~g}$ without causing negative effects on DM digestibility and metabolism.
\end{abstract}

Keywords: dry matter intake, digestibility, energy, hepatic, sheep

\section{INTRODUÇÃO}

Lisina e metionina são os aminoácidos mais limitantes para a produção de ruminantes, pois não estão presentes em quantidades satisfatórias nos ingredientes que compõem as dietas (Stieven et al., 2011), sendo necessária sua inclusão na forma sintética. A suplementação de dietas para ruminantes com aminoácidos livres não é eficaz, uma vez que estes são rapidamente degradados no

Recebido em 9 de dezembro de 2019

Aceito em 13 de maio de 2020

E-mail: carolina.am@hotmail.com 
rúmen e não chegam em quantidades suficientes ao intestino delgado para suprir as exigências de proteína metabolizável (Lapierre et al., 2006), o que, então, requer sua inclusão na forma protegida da degradação ruminal.

Quando a dieta possui quantidade excessiva de nutrientes ultrapassando as necessidades produtivas dos animais, tal excesso pode provocar alterações no metabolismo, visto que distúrbios metabólicos ocorrem devido ao desbalanço entre o ingresso de nutrientes e sua metabolização e excreção, o que causa queda na eficiência produtiva (Wittwer, 2000), sendo a quantidade de nutrientes absorvidos dependente da interação entre consumo e digestibilidade (Berchielli et al., 2006).

Diante do exposto, objetivou-se avaliar a inclusão de níveis de aminoácidos (lisina e metionina) protegidos da degradação ruminal na ração de borregas em crescimento e seus efeitos sobre o consumo de matéria seca, o balanço de nitrogênio e os parâmetros sanguíneos desses animais.

\section{MATERIAL E MÉTODOS}

O experimento foi conduzido na Fazenda Experimental Capim-Branco, pertencente à Faculdade de Medicina Veterinária da Universidade Federal de Uberlândia (UFU), em Uberlândia, MG, no período de setembro a outubro de 2016. O experimento foi submetido à análise pelo Comitê de Ética no Uso de animais de (Ceua), obtendo aprovação sob protocolo $\mathrm{n}^{\circ}$ $128 / 16$.

Utilizaram-se cinco borregas $1 / 2$ Dorper x $1 / 2$ Santa Inês, com aproximadamente oito meses de idade, peso médio de $50 \mathrm{~kg}$. As borregas foram vermifugadas, antes do início do período experimental, com monepantel via oral (1mL/10kg de peso corporal). Os animais foram alocados em gaiolas metabólicas individuais (padrão INCT), com piso de madeira ripado, dispostas de comedouro, bebedouro e saleiro. As gaiolas foram mantidas em galpão de piso cimentado e coberto por telhas de barro, com ventilação lateral e protegidas da radiação solar direta.

Os tratamentos foram sorteados sistematicamente segundo Sampaio (2002) e consistiram na inclusão de diferentes quantidades do produto (MicroPEARLS LM ${ }^{\circledR}$, Kemin - Brasil), sendo esse suplemento composto de aminoácidos (lisina e metionina) encapsulados (Tab. 1). A inclusão do referido produto foi de zero, oito, 16,24 e 32 gramas, fornecido diariamente. A ração foi balanceada segundo o NRC (Nutrient..., 2007), para ganhos de 250g/dia. Compunha-se de silagem de milho e concentrado na proporção 70C:30V (Tab. 1).

Tabela 1. Composição química e bromatológica $(\%)$ do concentrado e da silagem de milho

\begin{tabular}{lcccc}
\multicolumn{1}{c}{ Ingredientes } & Concentrado & Silagem & MicroPEARLS LM ${ }^{\circledR *}$ & Ração total $^{*}$ \\
\hline Milho triturado & $60,5^{* *}$ & - & - & - \\
Farelo de soja & $36,0^{* *}$ & - & - & - \\
Ureia & $1,0^{* *}$ & - & - & - \\
Sal mineral & $2,5^{* *}$ & - & - & - \\
Matéria seca & $90,2^{* *}$ & $32,2^{* *}$ & $99,0^{*}$ & $72,8^{* *}$ \\
Proteína bruta & $24,9^{* *}$ & $6,3^{* *}$ & $43,75^{*}$ & $19,36^{* *}$ \\
Fibra em detergente neutro & $24,8^{* *}$ & $54,6^{* *}$ & - & $33,74^{* *}$ \\
Fibra em detergente ácido & $7,0^{* *}$ & $32,6^{* *}$ & - & $14,68^{* *}$ \\
Extrato etéreo & - & - & $48,65^{*}$ & - \\
\hline
\end{tabular}

*Informações cedidas pelo fabricante; MicroPEARLS LM - 75\% de lisina e 25\% de metionina. ** Informações obtidas pelas análises feitas no laboratório de nutrição animal da UFU e do Instituto Federal de Uberaba.

O experimento teve duração de 75 dias, sendo dividido em cinco períodos. Cada período teve duração de 15 dias, sendo 10 dias destinados à adaptação dos animais e cinco dias destinados à coleta de amostras. A oferta de alimento foi realizada diariamente às oito e às 16 horas, sendo $50 \%$ do total em cada refeição. Os aminoácidos eram fornecidos integralmente na refeição matinal, sendo misturados manualmente ao alimento diretamente no cocho. As quantidades de aminoácidos eram pesadas em balança digital de precisão de 0,0001g. Todos os dias, as quantidades ofertadas e as sobras de alimento foram pesadas com o auxílio de balança 
eletrônica com precisão de cinco gramas, para acompanhamento do consumo pelos animais. As rações foram fornecidas de forma que houvesse sobra de $10 \%$ do total fornecido. As sobras de alimento foram coletadas e armazenadas em sacos plásticos devidamente identificados e mantidas em congelador a $-10^{\circ} \mathrm{C}$. Após o período de coleta, as amostras eram homogeneizadas individualmente e uma alíquota representativa era separada para realização das análises bromatológicas.

Abaixo das gaiolas metabólicas era mantido equipamento que permitia separação das fezes e da urina, possibilitando avaliação da digestibilidade. Para realizar coleta total de fezes, as gaiolas eram limpas todos os dias pela manhã, com o auxílio de espátula e vassoura. As fezes foram pesadas, homogeneizadas, e foi coletada alíquota representativa da amostra uma vez ao dia, sempre no período da manhã. As alíquotas foram acondicionadas em sacos plásticos, identificados e mantidos em congelador a $-10^{\circ} \mathrm{C}$.

Posteriormente foi feita a primeira secagem das amostras de sobras e fezes em estufa de circulação forçada de ar, a $55^{\circ} \mathrm{C}$, por 72 horas, até se obter peso constante. Feito isso, as amostras foram moídas, em moinho de facas do tipo Willey dotado com peneiras com crivos de diâmetro de $1 \mathrm{~mm}$. Logo após, as amostras foram levadas ao laboratório, onde foi realizada a segunda matéria seca, em estufa a $105^{\circ} \mathrm{C}$, por 24 horas, sendo, então, possível calcular a matéria seca definitiva delas e o teor dos nutrientes, e, posteriormente, a digestibilidade aparente, por meio das seguintes fórmulas (Maynard et al., 1984):

$$
\begin{aligned}
& \mathrm{CN}=(\text { Cons } \times \text { \%Cons })-(\text { Sob } \times \text { \%Sob }) \\
& \text { em que: }
\end{aligned}
$$

$\mathrm{CN}=$ consumo do nutriente $(\mathrm{kg}) ;$ Cons $=$ quantidade de alimento consumido $(\mathrm{kg}) ; \%$ Cons = teor do nutriente no alimento fornecido (\%); Sob $=$ quantidade de sobra retirada $(\mathrm{kg}) ; \%$ Sob $=$ teor do nutriente nas sobras (\%).

$$
\mathrm{DA}=\frac{(\mathrm{CN}-(\mathrm{Fez} \times \% \mathrm{Fez}))}{\mathrm{CN} \times 100}
$$

em que:

$\mathrm{DA}=$ digestibilidade aparente $(\%) ; \mathrm{Fez}=$ quantidade de fezes coletada $(\mathrm{kg}) ; \% \mathrm{Fez}=$ teor do nutriente nas fezes (\%); $\mathrm{CN}=$ consumo do nutriente $(\mathrm{kg})$.
Foram determinados os teores de proteína bruta (PB), de acordo com metodologias descritas por Silva e Queiroz (2002), e o consumo de matéria seca (CMS), obtidos pela diferença entre ofertado e sobras. $\mathrm{O}$ teor de $\mathrm{N}$ na urina foi calculado pelo método Kjeldahl (Silva e Queiroz, 2002). A quantidade de ácido gasto na titulação é utilizada para calcular o teor de $\mathrm{N}$ da amostra, por meio da fórmula:

$$
\% \mathrm{~N}=\frac{\mathrm{V} \times \mathrm{FC} \times \mathrm{N} \times 0,014}{\mathrm{P}} \times 100
$$

em que:

$\mathrm{V}=$ volume de $\mathrm{HCl} 0,1 \mathrm{~N}$ gasto na titulação; $\mathrm{FC}=$ fator de correção do $\mathrm{HCl} 0,1 \mathrm{~N} ; \mathrm{N}=$ normalidade do ácido utilizado na titulação; 0,014 = miliequivalente-grama do nitrogênio; $\mathrm{P}=$ peso da amostra em gramas. $\mathrm{O}$ balanço de $\mathrm{N}$, ou nitrogênio retido, foi obtido utilizando-se a fórmula proposta por Zeoula et al. (2006):

$\mathrm{BN}=[(\mathrm{N}$ fornecido $\mathrm{g}-\mathrm{N}$ das sobras $\mathrm{g})-$ ( $\mathrm{N}$ nas fezes $\mathrm{g}+\mathrm{N}$ na urina $\mathrm{g})]$.

Consequentemente, foi calculado o consumo de $\mathrm{N}$ $(\mathrm{CN})$ e a relação entre $\mathrm{N}$ ingerido e $\mathrm{N}$ retido (NING/NRET) por meio das fórmulas:

$$
\begin{gathered}
\mathrm{CN}=\mathrm{N} \text { fornecido }(\mathrm{g})-\mathrm{N} \text { das sobras }(\mathrm{g}) \\
\text { NING } \mathrm{NRET}^{-1}=\frac{B N}{C N}
\end{gathered}
$$

Para análise bioquímica do sangue, foi realizada uma coleta por dia, no período da manhã, antes da primeira oferta de alimento, durante três dias alternados de avaliação, totalizando três coletas por período (para fins de estatística, foi calculada a média dessas três coletas realizadas para obtenção do valor médio de cada animal em cada período). As coletas de sangue para avaliação dos componentes bioquímicos foram realizadas por venopunção jugular, com auxílio de tubos Vacutainer $^{\circledR}$ sem anticoagulante. As amostras de sangue coletadas foram centrifugadas a 3000rpm, por 10 minutos, sendo os soros separados em alíquotas em microtubos e armazenados em freezer a $-5^{\circ} \mathrm{C}$ para posterior análise laboratorial. Todas as amostras foram processadas em analisador bioquímico automatizado (Bioplus ${ }^{\circledR}$ 2000), utilizando-se kit comercial da Biotécnica ${ }^{\circledR}$.

Para determinar o perfil metabólico energético, foram analisados os metabólitos: glicose, colesterol, triglicerídeos, frutosamina, 
lipoproteína de alta densidade (HDL), lipoproteína de baixa densidade (LDL) e lipoproteína de muito baixa densidade (VLDL). Os valores de VLDL e LDL foram obtidos por cálculos propostos por Friedewald et al. (1972) a partir dos valores de colesterol total, HDL colesterol e triglicerídeos, conforme as equações:

$$
\begin{gathered}
\text { VLDL }=\text { TG } / 5 \\
\text { LDL=CT-HDL-VLDL, }
\end{gathered}
$$

em que: VLDL = lipoproteína de muito baixa densidade; $\mathrm{TG}=$ triglicerídeos; $\mathrm{LDL}=$ lipoproteína de baixa densidade; $\mathrm{CT}=$ colesterol total; HDL = lipoproteína de alta densidade. Para o perfil enzimático, foram analisados os metabólitos aspartato aminotransferase (AST), alanina aminotransferase (ALT), gamaglutamiltransferase (GGT) e fosfatase alcalina (FA). A avaliação glicêmica foi feita no último dia de coleta de cada período. As coletas de sangue foram realizadas às $8 \mathrm{~h}, 11 \mathrm{~h}, 14 \mathrm{~h}, 17 \mathrm{~h}$ e $20 \mathrm{~h}$, sendo as amostras coletadas por venopunção jugular com auxílio de Vacutainer $^{\circledR}$ e tubos contendo fluoreto e EDTA. A primeira coleta foi realizada antes da oferta de alimento, e a segunda oferta de alimento foi realizada após a última coleta de sangue (20h). Todas as amostras foram processadas em analisador bioquímico automatizado (Bioplus ${ }^{\circledR}$ 2000), usando-se kit comercial da Lab Test ${ }^{\circledR}$.

O delineamento experimental adotado foi $\mathrm{o}$ quadrado latino $5 \times 5$, sendo cinco tratamentos (inclusão $0,8,16,24$ e 32 gramas de MicroPEARLS LM ${ }^{\circledR}$ ), cinco animais e cinco períodos. Todos os dados foram testados quanto à normalidade (Shapiro e Wilk, 1965) e à homocedasticidade (Levene, 1960) das variâncias dos tratamentos. Aceitos esses pressupostos, os dados foram submetidos à análise de variância seguida da análise de regressão.

A glicemia foi analisada em um delineamento de quadrado latino $5 \times 5$, com arranjo de medidas repetidas no tempo (horário de coleta). Como, para essa variável, a condição de esfericidade não foi aceita, utilizou-se a análise de modelos mistos, em que foram avaliadas todas as estruturas de covariâncias (S) disponíveis no pacote do software SAS (2012) que modelam a dependência dos erros do modelo. Para selecionar a estrutura de covariâncias que melhor explique a correlação residual, foi utilizado o critério de informação de Akaike (AIC), sendo escolhida, para essa variável, a estrutura que resultou no menor valor de AIC após a análise (Silva et al., 2015). Tanto os tratamentos quanto os horários de coleta foram avaliados observando-se a significância dos efeitos linear e quadrático e a não significância da falta de ajuste do modelo, sendo a probabilidade de erro tipo I utilizada para tomada de decisão $5 \%$.

\section{RESULTADOS E DISCUSSÃO}

O consumo de matéria seca ( $\mathrm{kg} / \mathrm{dia})$ e o consumo em relação ao peso corporal apresentaram resposta linear positiva (Tab. 2), ou seja, quanto maior o nível de inclusão de aminoácidos protegidos na dieta, maior o consumo, este apresentando diferença de $16,94 \%$ entre o tratamento com $0 \mathrm{~g}$ e $32 \mathrm{~g}$ de aminoácido protegido. De acordo com o NRC (Nutrient..., 2007), recomenda-se que borregas nessa categoria consumam 1,39kg MS/dia; assim, os animais que receberam $32 \mathrm{~g}$ de aminoácidos protegidos apresentaram consumo $3,59 \%$ acima do recomendado, enquanto aqueles que não receberam os aminoácidos (controle, 0g de aminoácido) consumiram $13,95 \%$ abaixo do recomendado. O consumo de matéria seca em relação ao peso corporal (CMS/PC) ficou abaixo do recomendado pelo NRC (Nutrient..., 2007), que é de $2,78 \%$. Essa redução de $11 \%$ no CMS/PC pode ser em razão de o comitê se basear em animais geneticamente distintos dos utilizados no presente estudo.

O maior nível de aminoácidos protegidos na dieta pode ter proporcionado melhor atendimento às exigências de proteína metabolizável das borregas, enquanto os ingredientes utilizados no concentrado (farelos de soja e milho, silagem e ureia; Tab. 1) serviram como fonte de proteína degradável no rúmen (PDR), maximizando a síntese de proteína microbiana, uma vez que a síntese de proteína microbiana é dependente da concentração e da qualidade das fontes de energia e de nitrogênio dietético no rúmen (Ribeiro et al., 2001). Esse equilíbrio entre as fontes de proteína pode ter provocado aumento no consumo de matéria seca. 
Avaliação nutricional...

Tabela 2. Parâmetros nutricionais de borregas recebendo aminoácidos protegidos em diferentes proporções na dieta

\begin{tabular}{|c|c|c|c|c|c|c|c|c|c|c|}
\hline & \multicolumn{5}{|c|}{ Aminoácidos protegidos (g/dia) } & \multirow{2}{*}{$\mathrm{P}$} & \multirow{2}{*}{$\mathrm{Y}$} & \multirow{2}{*}{$\begin{array}{l}\mathrm{R}^{2} \\
(\%)\end{array}$} & \multirow{2}{*}{ Média } & \multirow{2}{*}{$\mathrm{CV}$} \\
\hline & 0 & 8 & 16 & 24 & 32 & & & & & \\
\hline CMS,kg/dia & 1,196 & 1,328 & 1,324 & 1,294 & 1,440 & 0,0258 & $\begin{array}{l}1,2256+ \\
0,005675 \mathrm{x}\end{array}$ & 67,65 & 1,31 & 8,07 \\
\hline $\begin{array}{l}\text { CMS/PM,kg/ } \\
\text { PC }^{0,75}\end{array}$ & 60,23 & 67,17 & 67,35 & 65,54 & 73,96 & 0,0014 & $\begin{array}{l}61,744+ \\
0,315925 \mathrm{x}\end{array}$ & 68,99 & 66,78 & 8,28 \\
\hline $\mathrm{CMS} / \mathrm{PC}, \%$ & 2,22 & 2,48 & 2,49 & 2,43 & 2,74 & 0,0098 & $\begin{array}{l}2,28280+ \\
0,01210 x\end{array}$ & 69,98 & 2,47 & 8,47 \\
\hline $\begin{array}{l}\text { DMS, } \\
\%\end{array}$ & 79,42 & 82,26 & 80,78 & 78,96 & 81,77 & 0,6741 & - & - & 80,64 & 3,02 \\
\hline
\end{tabular}

*CMS: consumo de matéria seca; PM: peso metabólico; PC: peso corporal; DMS: digestibilidade da matéria seca; CV: coeficiente de variação.

O suprimento de energia que chega ao intestino para o animal é proveniente, principalmente, da digestão da proteína, do carboidrato e dos ácidos graxos de cadeia longa (Berchielle et al., 2001). Dessa forma, os aminoácidos protegidos podem ter promovido elevado aporte energético para o intestino delgado, permitindo que a energia sobrepassante pudesse ser utilizada para o crescimento, incrementando o consumo por parte dos animais. Como a dieta fornecida era altamente palatável, o consumo foi, mais uma vez, beneficiado.

Segundo Alves (2004), quando a proteína metabolizável é de alta qualidade, ou seja, rica e com o perfil de aminoácidos essenciais adequado, o teor de proteína bruta da ração pode ser reduzido, a eficiência de utilização da proteína metabolizável é otimizada, a excreção de ureia e de outros compostos nitrogenados é reduzida (menor gasto energético) e o desempenho animal é maximizado. Antongiovanni et al. (2002) não observaram melhorias no consumo de matéria seca com a adição de níveis de metionina e lisina protegidas na dieta de cordeiros com dois meses de idade.

Em dietas com valores de digestibilidade menores que $66 \%$, a ingestão de alimentos é determinada por fatores físicos, ou seja, está relacionada à distensão física do rúmen-retículo. Já em dietas com valores superiores a $66 \%$ de digestibilidade, são os fatores fisiológicos que controlam a ingestão de alimentos, ou seja, o balanço energético ou nutricional da dieta (Mertens, 1994). No presente estudo, a média encontrada para a digestibilidade da matéria seca (DMS) foi de 80,64 e não apresentou diferença entre os tratamentos. A alta digestibilidade observada pode ter ocorrido em razão de $70 \%$ da dieta ser composta por concentrado, ou seja, grãos altamente fermentáveis no rúmen.

De acordo com o NRC (Ruminant..., 1985), crescimento microbiano é dependente da relação entre tamanho de partícula, volume e taxa de passagem do alimento pelo rúmen, sendo que aumento na taxa de passagem reduz a idade média da população microbiana devido à remoção dos organismos maduros e, consequentemente, reduz a demanda energética da microbiota. Dessa forma, há maior eficiência no uso da energia do sistema para o crescimento microbiano (Polan, 1988). Assim, a digestibilidade manteve-se elevada em todos os tratamentos, mesmo com a mudança observada no CMS (Tab. 2), indicando que o elevado aporte energético da dieta promoveu aumento no crescimento microbiano e na taxa de passagem. Além disso, o concentrado tinha ureia em sua composição (Tab. 1), sendo essa fonte de nitrogênio prontamente degradada no rúmen e utilizada na formação de proteína microbiana. Han et al. (1996) avaliaram dieta com e sem a inclusão de lisina e metionina protegidas em ovelhas com peso médio de $50 \mathrm{~kg}$ e observaram maior DMS com a inclusão dos aminoácidos, passando de $69,4 \pm 1,75$ para $72,6 \pm 2,20 \%$.

O balanço de nitrogênio é indicativo do metabolismo proteico e constitui importante parâmetro na avaliação de alimentos, o que permite avaliar se o animal se encontra em equilíbrio quanto aos seus compostos nitrogenados (Guimarães Jr. et al., 2007). Os valores encontrados para $\mathrm{N}$ ingerido apresentaram equação linear positiva (Tab. 3). Esse consumo de nitrogênio está relacionado com o aumento no CMS (Tab. 2) e com o aumento no nível da inclusão suplementar dos aminoácidos protegidos no concentrado. Moreno et al. (2010) observaram 
consumo de $\mathrm{N}$ de $32,60 \mathrm{~g} / \mathrm{dia}$ para ovinos alimentados com $60 \%$ de concentrado com $19,0 \%$ de PB. Geron et al. (2015) encontraram valores de
$12,38 \mathrm{~g} /$ dia trabalhando com $40 \%$ de concentrado com $13,0 \%$ de PB.

Tabela 3. Consumo, excreção e balanço de nitrogênio de borregas recebendo aminoácidos protegidos em diferentes proporções na dieta

\begin{tabular}{|c|c|c|c|c|c|c|c|c|c|c|}
\hline & \multicolumn{5}{|c|}{ Aminoácidos protegidos (g/dia) } & & \multirow{2}{*}{ Y } & \multirow{2}{*}{$\begin{array}{l}\mathrm{R}^{2} \\
(\%)\end{array}$} & \multirow{2}{*}{ Média } & \multirow{2}{*}{$\mathrm{CV}$} \\
\hline & 0 & 8 & 16 & 24 & 32 & & & & & \\
\hline $\mathrm{CN}, \mathrm{g} / \mathrm{dia}$ & 33,26 & 41,70 & 42,32 & 41,13 & 47,48 & 0,0047 & $\begin{array}{c}135,6044+ \\
0,348475 x\end{array}$ & 74,73 & 41,18 & 11,19 \\
\hline $\begin{array}{l}\mathrm{N} \text { FEZ, } \\
\text { g/dia }\end{array}$ & 6,01 & 6,26 & 6,29 & 6,34 & 6,66 & 0,5874 & - & - & 6,31 & 16,65 \\
\hline $\begin{array}{l}\mathrm{N} \text { URI, } \\
\text { g/dia }\end{array}$ & 8,87 & 8,87 & 8,48 & 9,87 & 8,33 & 0,6932 & - & - & 8,89 & 30,09 \\
\hline $\begin{array}{l}\mathrm{BN}, \\
\mathrm{g} / \mathrm{dia}\end{array}$ & 17,68 & 25,14 & 27,23 & 23,41 & 30,52 & 0,0052 & $\begin{array}{c}20,00840+ \\
0,299325 x\end{array}$ & 62,74 & 24,79 & 26,87 \\
\hline $\mathrm{NR} / \mathrm{CN}$ & 0,53 & 0,62 & 0,67 & 0,61 & 0,67 & 0,8741 & - & - & 0,62 & 16,47 \\
\hline
\end{tabular}

*CN: consumo de nitrogênio; N FEZ: nitrogênio fecal; N URIN: nitrogênio na urina; BN: balanço de nitrogênio; NR/NI: relação entre nitrogênio retido e consumo de nitrogênio; $C V$ : coeficiente de variação.

Como não houve diferença $(\mathrm{P}>0,05)$ para a DMS, o aumento na ingestão de $\mathrm{N}$ também não influenciou a excreção do $\mathrm{N}$ fecal e urinário (Tab. 3). As perdas de $\mathrm{N}$ fecal corresponderam a $15,32 \%$ do total de $\mathrm{N}$ ingerido. Os altos valores encontrados para DMS (Tab. 2) proporcionaram melhor aproveitamento do $\mathrm{N}$ ingerido, diminuindo sua excreção via fezes. A excreção de $\mathrm{N}$ nas fezes indica que maior conservação dos compostos nitrogenados ocorre quando se utilizam dietas com menores teores proteicos, pois $\mathrm{o}$ aumento da $\mathrm{PB}$ da dieta pode ocasionar excesso na liberação de ureia (Tab. 4), via urina, constituindo desperdício de proteína.

Já as perdas de nitrogênio via urina corresponderam a $21,58 \%$ do total ingerido. Isso indica que o aumento no $\mathrm{N}$ ingerido resultou em nitrogênio sobrepassante no rúmen, fazendo com que o animal concentrasse sua eliminação via urina e, assim, fossem evitadas possíveis intoxicações por amônia. Esse mecanismo resulta em maior gasto de energia pelo fígado, considerando que a síntese da ureia a partir da amônia é processo energeticamente dispendioso, estando calculado em ovinos em aproximadamente 88,4 $\mathrm{kcal} \mathrm{mol}^{-1}$ (Martin e Blaxter, 1965). Moreno et al. (2010) encontraram perdas de 40,74 e 22,20\% para $\mathrm{N}$ fecal e urinário, respectivamente.

$\mathrm{O}$ balanço de nitrogênio (BN) apresentou equação linear positiva em resposta à inclusão dos aminoácidos na dieta (Tab. 3). O fato de o BN ter sido positivo indica que os animas não necessitaram deslocar reservas proteicas corporais para suprir suas exigências nutricionais. Segundo Zeoula et al. (2006), maiores valores de BN em dietas com elevado teor de concentrado podem se dar em razão do maior consumo e digestibilidade da PB. De fato, no presente estudo, observou-se que os animais que receberam maiores níveis de lisina e metionina protegidas apresentaram maior CMS e BN (Tab. 2 e 3).

Diante do exposto, nota-se que a inclusão de lisina e metionina protegidas até $32 \mathrm{~g}$ na dieta de borregas aumenta o CMS sem afetar negativamente sua digestibilidade, além de aumentar a ingestão de nitrogênio. $\mathrm{O}$ excesso de $\mathrm{N}$ dietético fez com que houvesse aumento na sua excreção via urina, o que pode ter causado maior gasto energético pelos animais. Os metabólitos energéticos avaliados não foram influenciados pelos níveis de aminoácidos (Tab. 4).

Os níveis de colesterol ficaram $41,42 \%$ abaixo do valor mínimo de referência (Tab. 4). Colesterol e ureia utilizam o mesmo substrato para sua formação, o piruvato. $\mathrm{O}$ piruvato dá origem à Acetil-CoA, e essa molécula é responsável pelo enlongamento da cadeia lipídica, enquanto para a formação da ureia, é utilizado o oxalacetato, que, por sua vez, também é derivado do piruvato (Motta, 2011). Como houve aumento nos níveis de ureia sanguínea devido à necessidade de excretar a amônia, houve redução na formação do colesterol em razão do possível desvio do substrato piruvato. Além disso, o colesterol é constituinte das lipoproteínas que são sintetizadas no fígado e no intestino delgado e atuam no 
transporte de lipídios no organismo (Kaneko et al., 2008). Para que ocorra formação das lipoproteínas, há aumento da síntese de colesterol no intestino delgado, o que se dá por efeito da inclusão de lipídeos nas dietas (Bauchart, 1993). Como não houve essa inclusão, os níveis de lipoproteínas também não foram alterados.

A lipoproteína de alta densidade (HDL) é responsável pelo transporte do colesterol dos tecidos extra-hepáticos para o fígado, enquanto as lipoproteínas de baixa densidade (LDL) realizam o transporte no sentido contrário (Campbell, 2001). Com a diminuição nos níveis de colesterol, houve consequentemente queda de $13 \%$ e $51 \%$ na concentração do HDL e LDL, respectivamente (Tab. 4), mantendo-se abaixo dos valores de referência. Já a lipoproteína de muito baixa densidade (VLDL) é responsável pelo transporte dos triglicerídeos. Esta variável não apresentou diferença estatística entre os tratamentos e permaneceu $10 \%$ abaixo do valor mínimo recomendado. Como os níveis das lipoproteínas mantiveram-se baixos, as relações LDL $\mathrm{HDL}^{-1} \mathrm{e}$ CT HTL ${ }^{-1}$ também apresentaram o mesmo padrão de resposta (Tab. 4). As lipoproteínas de baixa e muito baixa densidade, quando presentes em baixas concentrações, reduzem os riscos de doenças nos animais (Araújo et al., 2009).

Tabela 4. Perfil metabólico energético de borregas recebendo aminoácidos protegidos em diferentes proporções na dieta

\begin{tabular}{|c|c|c|c|c|c|c|c|c|c|}
\hline & \multicolumn{5}{|c|}{ Aminoácidos protegidos (g/dia) } & \multirow{2}{*}{$\mathrm{P}$} & \multirow{2}{*}{ VR } & \multirow{2}{*}{ Média } & \multirow{2}{*}{$\mathrm{CV}$} \\
\hline & 0 & 8 & 16 & 24 & 32 & & & & \\
\hline $\begin{array}{l}\text { Colesterol, } \\
\mathrm{mg} / \mathrm{dL}\end{array}$ & 30,76 & 36,24 & 28,64 & 27,82 & 28,84 & 0,4158 & $52-76$ & 30,46 & 25,83 \\
\hline $\begin{array}{l}\text { Triglicerídeo, } \\
\mathrm{mg} / \mathrm{dL}\end{array}$ & 16,48 & 16,76 & 10,78 & 11,18 & 12,36 & 0,5842 & $9-30$ & 13,51 & 37,17 \\
\hline $\begin{array}{l}\text { Frutosamina, } \\
\mu \mathrm{mg} / \mathrm{dL}\end{array}$ & 216,51 & 193,05 & 204,58 & 206,65 & 197,65 & 0,3571 & $170-174$ & 203,69 & 20,17 \\
\hline $\mathrm{LDL}, \mathrm{mg} / \mathrm{dL}$ & 14,76 & 14,65 & 16,42 & 17,51 & 12,12 & 0,3369 & $29,4-65,9^{*}$ & 15,09 & 34,64 \\
\hline VLDL, mg/dL & 3,29 & 3,35 & 2,15 & 2,23 & 2,47 & 0,8897 & $3,0-4,0$ & 2,70 & 37,17 \\
\hline $\mathrm{HDL}, \mathrm{mg} / \mathrm{dL}$ & 34,98 & 35,16 & 38,10 & 38,24 & 38,50 & 0,14785 & $43-53$ & 36,99 & 17,56 \\
\hline LDL/HDL & 0,38 & 0,36 & 0,42 & 0,44 & 0,31 & 0,4183 & - & 0,38 & 22,90 \\
\hline $\mathrm{CT} / \mathrm{HDL}$ & 0,90 & 1,20 & 0,74 & 0,73 & 0,76 & 0,5687 & - & 0,87 & 39,21 \\
\hline
\end{tabular}

LDL: lipoproteínas de baixa densidade; VLDL: lipoproteínas de muito baixa densidade; HDL: lipoproteínas de alta densidade; CT: colesterol; VR: valor de referência segundo Kaneko et al. (2008); *valor de referência segundo Ghoreishi et al. (2007); CV: coeficiente de variação.

Não houve diferença entre os tratamentos para frutosamina, que se manteve $18 \%$ acima do proposto por Kaneko et al. (2008). A frutosamina é uma cetoamina estável, formada quando a glicose reage não enzimaticamente com a proteína, principalmente a albumina. Quando a quantidade de proteína da dieta está dentro da normalidade, os índices de frutosamina estão relacionados aos níveis de glicose plasmática (Kaneko et al., 2008). A presença de grandes quantidades de amido na dieta (Tab. 1) vindo do farelo de milho e da silagem de milho contribuiu para esses resultados.

A curva glicêmica dos animais apresentou interação entre os tratamentos e o horário de coleta, apresentando equação quadrática em todos os tratamentos, com exceção dos animais que receberam $8 \mathrm{~g}$ de aminoácidos protegidos (Tab. 5). Observa-se que os picos ocorreram nas horas subsequentes à alimentação, vindos a declinar após longo período em jejum (próximo às 20 horas). De fato, em ruminantes, o pico de concentração de glicose ocorre nesse período após alimentação, pois a glicose é sintetizada no fígado a partir de propionato, aminoácidos glicogênicos, lactato e outros precursores (Caldeira, 2005). A glicose permaneceu dentro dos valores de referência, indicando um bom aproveitamento energético vindo do carboidrato, uma vez que o farelo de milho é altamente digestível, e do amido da silagem de milho. 
Tabela 5. Interação entre níveis de aminoácidos protegidos e horário de coleta sobre a concentração de glicose no sangue de borregas em crescimento

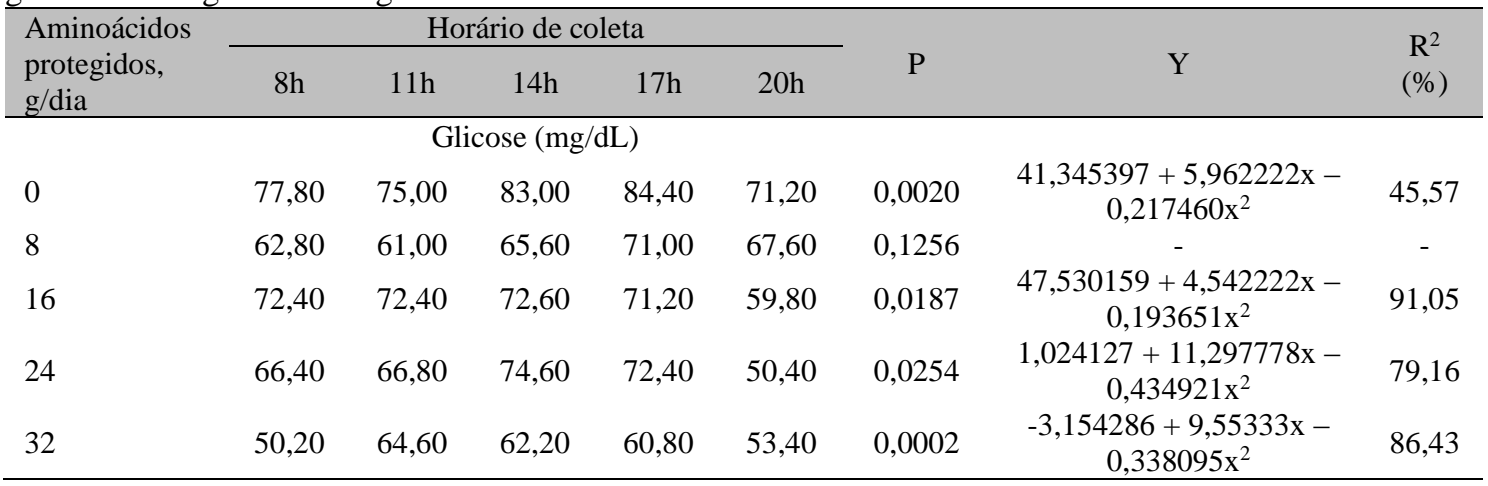

Média: 67,58mg/dL; CV: 10,83; VR: 50 - 80mg/dL.

De acordo com González et al., (2000), em ruminantes a síntese de glicose depende de adequado funcionamento hepático. Como as enzimas avaliadas aspartato aminotransferase e alanina aminotransferase mantiveram-se dentro dos valores recomendados (Tab. 6), os níveis de glicose também se mantiveram estáveis. Entretanto, a gamaglutamiltransferase é a enzima mais representativa para as funções hepáticas e manteve-se elevada, correlacionando com os valores elevados encontrados para excreção de nitrogênio (Tab. 3).

Não houve diferença $(\mathrm{P}>0,05)$ entre os tratamentos para as enzimas avaliadas (Tab. 6). A avaliação das enzimas hepáticas tem como objetivo observar a ocorrência de possíveis lesões hepáticas. A enzima aspartato aminotransferase (AST) está diretamente ligada ao estado hepático, sendo usada como indicador de lesões no fígado (Duncan e Prasse, 1982). Esta variável mantevese dentro dos valores de referência. Madureira et al. (2013) observaram valores de AST para ovinos da raça Dorper de até 12 meses de idade de $138,0 \pm 71,0$ UI L. A fosfatase alcalina manteve-se dentro da faixa recomendada por Kaneko et al. (2008). Esta enzima encontra-se no fígado, nos túbulos renais, no intestino e no tecido ósseo, que catalisa a hidrólise alcalina de vários substratos (Meyer; Harvey, 1998). Madureira et al. (2013) encontraram valores de 257,0 $\pm 125,0$ (UI L) para fosfatase alcalina em cordeiros de até 12 meses de idade.

Tabela 6. Perfil metabólico enzimático de borregas recebendo aminoácidos protegidos em diferentes proporções na dieta

\begin{tabular}{|c|c|c|c|c|c|c|c|c|c|}
\hline & \multicolumn{5}{|c|}{ Aminoácidos protegidos (g/dia) } & \multirow{2}{*}{$\mathrm{P}$} & \multirow{2}{*}{ VR } & \multirow{2}{*}{ Média } & \multirow{2}{*}{$\mathrm{CV}$} \\
\hline & 0 & 8 & 16 & 24 & 32 & & & & \\
\hline AST, U/L & 166,10 & 180,32 & 182,84 & 123,90 & 161,68 & 0,5263 & $68-387$ & 162,96 & 31,89 \\
\hline ALT, U/L & 16,22 & 13,10 & 13,68 & 18,70 & 15,42 & 0,4578 & 4-19 & 15,42 & 26,02 \\
\hline $\mathrm{FA}, \mathrm{U} / \mathrm{L}$ & 365,78 & 359,10 & 357,44 & 308,78 & 321,76 & 0,6325 & $68-387$ & 342,57 & 14,78 \\
\hline GGT, U/L & 58,85 & 65,69 & 72,58 & 61,86 & 52,24 & 0,5532 & $20-52$ & 62,64 & 16,69 \\
\hline
\end{tabular}

AST: aspartato aminotransferase; ALT: alanina aminotransferase; FA: fosfatase alcalina; GGT: gamaglutamiltransferase; VR: valor de referência segundo Kaneko et al. (2008); CV: coeficiente de variação.

A gamaglutamiltransferase (GGT) está presente em todas as células, com exceção do músculo. Segundo Kaneko et al. (2008), está associada com o metabolismo do glutationa e é uma enzima encontrada na membrana celular, portanto não está visivelmente elevada na doença hepática aguda como ocorre com as transaminases. É encontrada em altas concentrações no fígado e liberada na corrente sanguínea quando ocorre algum dano às enzimas hepáticas. A GGT apresentou aumento médio de $17 \%$ do limite máximo proposto. Pode-se relacionar esse aumento com os níveis de $\mathrm{N}$ urinário (Tab. 3), uma vez que essa excreção pode ter ocasionado uma sobrecarga no fígado, elevando os níveis de GGT. Porém, não foram observados sintomas 
relacionados a problemas hepáticos no presente estudo. Segundo Madureira et al. (2013), ovinos de até 12 meses de idade apresentaram GGT de $93,0 \pm 19,0$.

\section{CONCLUSÃO}

A inclusão de 32 gramas por dia de aminoácidos na ração promoveu aumento no consumo de matéria seca, sem alterar a digestibilidade da matéria seca e o balanço de nitrogênio, bem como manteve os animais bioquimicamente estáveis, sem alterações hepáticas e renais.

\section{REFERÊNCIAS}

ALVES, D. Nutrição aminoacídica de bovinos. Rev. Bras. Agrociênc., v.10, p.265-271, 2004.

ANTONGIOVANNI, M.; ACCIAIOLI, A.; FRANCI, O. et al. Field bean (Vicia faba var. minor) as a protein feed for growing lambs with and without protected lysine and methionine supplementation. Ital. J. Anim. Sci., v.1, p.229238, 2002.

ARAUJO, R.C.; PIRES, A.V.; SUSIN, I.; MENDES, C.Q. et al. Postpartum ovarian activy of Santa Inês lactating ewes fed diets containing soybean hulls as replacement for coastcross (Cynodon sp.) hay. Small Ruminant Res., v.81, p.126-131, 2009.

BAUCHART, D. Lipid absorption and transport in ruminants. J. Dairy Sci., v.76, p.3864-3881, 1993.

BERCHIELLI, T.T.; GARCIA, A.V.; OLIVEIRA, S.G. Principais técnicas de avaliação aplicadas em estudo de nutrição. In: BERCHIELLI, T.T.; PIRES, A.V.; OLIVEIRA, S.G (Eds.). Nutrição de ruminantes. Jaboticabal: FAPESP, 2006. p.397-421.

CALDEIRA, R.M. Monitorização da adequação do plano alimentar e do estado nutricional em ovelhas. Rev. Port. Ciênc. Vet., v.100, p.125-139, 2005.

CAMPBELL, M.K. Bioquímica. 3.ed. Porto Alegre: Artmed, 2001. p.546-581.

DUNCAN, J.R.; PRASSE, K.W. Patologia clínica veterinária. Rio de Janeiro: Guanabara Koogan, 1982. 217p.
FRIEDEWALD, W.T.; LEVV, R.I.; FREDRICKSON, D.S. Estimation of the concentration of low-density lipoprotein in plasma, without use of the preparative ultracentrifuge. Clin. Chem., v.18, p.499-502, 1972.

GERON, L.J.V.; COSTA, F.G.; SANTOS, R.H.E. et al. Balanço de nitrogênio em cordeiros alimentados com rações contendo diferentes teores de concentrado. Semin. Ciênc. Agr., v.36, p.1609-1622, 2015

GHOREISHI, S.M.; ZAMIRI, M.J.; ROWGHANI, E. et al. Effect of a calcium soap of fatty acids on reproductive characteristics and lactation performance of fattailed sheep. Pak. J. Biol. Sci., v.10, p.2389-2395, 2007.

GONZÁLEZ， F.H.D.; CONCEIÇÃO， T.R.; SIQUEIRA, A.J.S. et al. Variações sanguíneas de ureia, creatinina, albumina e fósforo em bovinos de corte no Rio Grande do Sul. Hora Vet., v.20, p.59-62, 2000.

GUIMARÃES JÚNIOR, R.; GONÇALVES, L.C.; PEREIRA, L.G.R. et al. Balanço de nitrogênio em ovinos alimentados com silagens de três genótipos de milheto Pennisetum glaucum (L.) R. Br. In: REUNIÃO ANUAL DA SOCIEDADE BRASILEIRA DE ZOOTECNIA, 44., 2007, Jaboticabal. Anais... Jaboticabal: SBZ, 2007. 1 CD-ROM.

HAN, I.K.; HA, J.K.; LEE, S.S. et al. Effect of supplementing rúmen-protected lysine and methionine on ruminal 21 characteristics and nutriente digestibility in sheep. Asian-australas. J. Anim. Sci., v.9, p.223-229, 1996.

KANEKO, J.J.; HARVEY, J.W.; BRUSS, M.L. Clinical biochemistry of domestic animals. 6.ed. San Diego: Academic Press. 2008. 916p

LAPIERRE, H.; PACHECO, D.; BERTHIAUME, R. et al. What is the supply of amino acids for a dairy cow? J. Dairy Sci., v.89, p.1-14, 2006.

LEVENE, H. Robust tests for the equality of variance. In: OLKIN, I. (Ed.). Contributions to probability and statistics. Palo Alto, California: Stanford University Press, 1960. p.278-292.

MADUREIRA, K.M.; GOMES, V.; BARCELOS, B. et al. Parâmetros hematológicos e bioquímicos de ovinos da raça Dorper. Semin. Ciênc. Agr., v.34, p.811-816, 2013. 
MARTIN, A.K.; BLAXTER, K.L. The energy cost of urea synthesis in sheep. In: BLAXTER, K.L. (Ed.). Energy metabolism. London: Academic Press, 1965. p.83-91.

MAYNARD, L.A.; LOOSLI, B.S.; HINTZ, H.F. et al. Nutrição animal. 3.ed. Rio de Janeiro: Freitas Bastos, 1984. 726p.

MERTENS, D.R. Regulation of forage intake. In: FAHEY Jr., G.C., (Ed.). Forage quality, evaluation and utilization. Madison: American Society of Agronomy, 1994. p.450-493.

MEYER, D.J.; HARVEY, J.W. Evaluation of hepatobiliary system and skeletal muscle and lipid disorders. Philadelphia: W.B. Sauders, 1998. p.157-186.

MORENO, G.M.B.; SOBRINHO, A.G.S.; LEÃO, A.G. et al. Desempenho, digestibilidade e balanço de nitrogênio em cordeiros alimentados com silagem de milho ou cana-de-açúcar e dois níveis de concentrado. Rev. Bras. Zootec., v.39, p.853-860, 2010.

MOTTA, V.T. Bioquímica. 2.ed. Rio de Janeiro: Medbook, 2011. 488p.

NUTRIENT requirements of small ruminants. Washington, D.C.: National Academy Press, 2007. 362p.

POLAN, C.E. Dietary protein and microbial protein contribution. J. Nutr., v.18, p.242-248, 1988.

RIBEIRO, K.G.; GARCIA, R.; PEREIRA, O.G.; VALADARES FILHO, S.C. et al. Eficiência microbiana, fluxo de compostos nitrogenados no abomaso, amônia e $\mathrm{pH}$ ruminais em bovinos recebendo dietas contendo feno de capim-Tifton 85 de diferentes idades de rebrota. Rev. Bras. Zootec., v.30, p.581-588, 2001.
RUMINANT nitrogen usage. Washington, D.C.: National Academy Press, 1985. 138p.

SAMPAIO, I.B.M. Estatística aplicada experimentação animal. 2.ed. Belo Horizonte: FEPMVZ, 2002. 265p.

SAS user's guide: statistics, version 9.4. Cary: SAS Institute, 2012.

SHAPIRO, S.S.; WILK, M.B. An analysis of variance teste for normality. Biometrika, v.52, p.591-611, 1965.

SILVA, D.J.; QUEIROZ, A.C. Análise de alimentos (métodos químicos e biológicos). Viçosa: UFV, 2002. 235p.

SILVA, E.N.; DUARTE, J.B.; REIS, A.J. Seleção da matriz de variância-covariância residual na análise de ensaios varietais com medidas repetidas em cana-de-açúcar. Ciênc. Rural, v.45, p.993999, 2015.

STIEVEN, I.C.B.; ROSSI JUNIOR, P.; FERNANDES, S.R. et al. Exigência e absorção de aminoácidos em bovinos. PUBVET, v.5, n.7, 10p., 2011.

WITTWER, F. Diagnóstico dos desequilíbrios metabólicos de energia em rebanhos bovinos. In: GONZÁLEZ, F.H.D. O perfil metabólico em uso em nutrição e doenças nutricionais. Porto Alegre: Universidade Federal do Rio Grande do Sul, 2000.

ZEOULA, L.M.; FERELI, F.; PRADO, I.N. et al. Digestibilidade e balanço de nitrogênio de rações com diferentes teores de proteína degradável no rúmen e milho moído como fonte de amido em ovinos. Rev. Bras. Zootec., v.35, p.2179-2186, 2006. 